\title{
Non-occlusive Mesenteric Ischemia with Diabetic Ketoacidosis and Lactic Acidosis Following the Administration of a Sodium Glucose Co-transporter 2 Inhibitor
}

\author{
Naoki Gocho, Ema Aoki, Chiho Okada, Kazuki Omura, Takeshi Hirashima, Natsuko Suzuki, \\ Hideki Tanaka and Yasue Omori
}

\begin{abstract}
We herein describe a patient with non-occlusive mesenteric ischemia (NOMI) potentially associated with the administration of a sodium glucose co-transporter 2 (SGLT2) inhibitor. A 60-year-old man with type 1 diabetes was transferred to our hospital due to vomiting and respiratory distress. He was treated with insulin, metformin and a SGLT2 inhibitor, which had recently been added. He was diagnosed with intestinal ischemia complicated by diabetic ketoacidosis and lactic acidosis. Urgent exploratory surgery was performed, and the gangrenous bowel was resected. Histological findings confirmed the diagnosis of NOMI. The administration of SGLT2 inhibitors therefore requires certain exceptions for type 1 diabetes and cautious monitoring for the occurrence of these possible adverse effects.
\end{abstract}

Key words: non-occlusive mesenteric ischemia, SGLT2 inhibitor, diabetic ketoacidosis, lactic acidosis

(Intern Med 55: 1755-1760, 2016)

(DOI: 10.2169/internalmedicine.55.6338)

\section{Introduction}

Non-occlusive mesenteric ischemia (NOMI) is mesenteric underperfusion due to reactive vascular spasm without demonstrable organic occlusion of the mesenteric vasculature (1). NOMI is a life-threatening disorder with a mortality rate of up to $70 \%$ and requires a prompt diagnosis and, very often, surgical treatment $(2,3)$. NOMI accounts for $20-$ $30 \%$ of all cases of acute mesenteric ischemia and occurs most frequently in elderly patients with risk factors that include the use of vasoconstrictor agents such as digoxin or catecholamines, long-term hemodialysis, post-heart surgery, impaired cardiac output, volume depletion, and renal failure (4). In addition, several recent case reports (5-9) have described NOMI associated with diabetic ketoacidosis.

Sodium glucose co-transporter 2 (SGLT2) inhibitors are a novel class of oral hypoglycemic agents. This drug blocks the renal absorption of glucose via the proximal renal tubules and reduces not only the plasma glucose concentra- tion, but also body weight and fat mass. Due to its unique mechanism of action, SGLT2 inhibitors may induce hypoglycemia, urinary tract and genital infections, and increased urination, which can lead to dehydration and an altered renal function as adverse effects, although these are usually well tolerated and rarely lead to discontinuation of the drug (10).

We herein present a case of NOMI with type 1 diabetes complicated by severe dehydration, acute kidney injury, diabetic ketoacidosis and lactic acidosis. The medications in use included insulin, metformin and a SGLT2 inhibitor, which had been added to the regimen very recently. We speculate that the SGLT2 inhibitor contributed to the onset of NOMI and diabetic ketoacidosis in our case. This is the first report of NOMI potentially associated with the use of a SGLT2 inhibitor. The administration of SGLT2 inhibitors requires certain exceptions for type 1 diabetes and cautious monitoring for these adverse effects. 
Table. Laboratory Data on Admission.

\begin{tabular}{|c|c|c|c|}
\hline \\
\hline \multicolumn{4}{|l|}{$\begin{array}{l}\text { Urinalysis } \\
\text { Protein }\end{array}$} \\
\hline \multicolumn{4}{|c|}{ Creatine kinase } \\
\hline Occult blood & $(-)$ & Total bilirubin & $0.3 \mathrm{mg} / \mathrm{dL}$ \\
\hline Ketone & $(2+)$ & Aspartate aminotransferase & 17 IU/L \\
\hline Amylase & $1,137 \mathrm{U} / \mathrm{L}$ & Alanine aminotransferase & $20 \mathrm{IU} / \mathrm{L}$ \\
\hline \multicolumn{2}{|l|}{ Arterial blood gas analysis } & Alkaline phosphatase & $258 \mathrm{IU} / \mathrm{L}$ \\
\hline $\mathrm{pH}$ & 7.278 & Amylase & $1,685 \mathrm{U} / \mathrm{L}$ \\
\hline \multirow{2}{*}{$\mathrm{PaO}_{2}$} & 102.6 Torr & Amylase (Salivary type) & $1,558 \mathrm{IU} / \mathrm{L}$ \\
\hline & 22.4 Torr & Lipase & $183 \mathrm{U} / \mathrm{L}$ \\
\hline $\mathrm{HCO}_{3}$ & $10.2 \mathrm{mEq} / \mathrm{L}$ & Elastase 1 & $310 \mathrm{ng} / \mathrm{dL}$ \\
\hline \multirow{2}{*}{$\begin{array}{l}\text { Base excess } \\
\text { Anion gap }\end{array}$} & \multirow{2}{*}{$\begin{array}{l}-14.5 \mathrm{mEq} / \mathrm{L} \\
42.6 \mathrm{mEq} / \mathrm{L}\end{array}$} & C-reactive protein & $7.33 \mathrm{mg} / \mathrm{dL}$ \\
\hline & & Plasma Glucose & $1,218 \mathrm{mg} / \mathrm{dL}$ \\
\hline \multicolumn{2}{|l|}{ Complete blood count } & $\mathrm{HbAlc}$ & $8.7 \%$ \\
\hline \multirow{2}{*}{$\begin{array}{l}\text { White blood cells } \\
\text { Red blood cells }\end{array}$} & $13,500 / \mu \mathrm{L}$ & Serum-C peptide & $<0.10 \mathrm{ng} / \mathrm{mL}$ \\
\hline & $456 \times 10^{4} / \mu \mathrm{L}$ & TSH & $1.24 \mu \mathrm{IU} / \mathrm{mL}$ \\
\hline Hemoglobin & $13.7 \mathrm{~g} / \mathrm{dL}$ & FT3 & $1.52 \mathrm{pg} / \mathrm{mL}$ \\
\hline Platelets & $31.4 \times 10^{4} / \mu \mathrm{L}$ & FT4 & $0.81 \mathrm{ng} / \mathrm{dL}$ \\
\hline \multicolumn{2}{|l|}{ Blood chemistry } & Acetoacetic acid & $7,343 \mu \mathrm{mol} / \mathrm{L}$ \\
\hline Total protein & $6.6 \mathrm{~g} / \mathrm{dL}$ & 3-hydroxybutylic acid & $18,350 \mu \mathrm{mol} / \mathrm{L}$ \\
\hline Albumin & $3.9 \mathrm{~g} / \mathrm{dL}$ & Total ketone body & $25,693 \mu \mathrm{mol} / \mathrm{L}$ \\
\hline Blood urea nitrogen & $78.1 \mathrm{mg} / \mathrm{dL}$ & Lactic acid & $55.1 \mathrm{mg} / \mathrm{dL}$ \\
\hline Creatinine & $4.06 \mathrm{mg} / \mathrm{dL}$ & D-dimers & $1.3 \mu \mathrm{g} / \mathrm{mL}$ \\
\hline Uric acid & $13.2 \mathrm{mg} / \mathrm{dL}$ & Procalcitonin & $9.9 \mathrm{ng} / \mathrm{mL}$ \\
\hline Sodium & $128 \mathrm{mEq} / \mathrm{L}$ & Anti GAD Ab & $52.3 \mathrm{U} / \mathrm{mL}$ \\
\hline Potassium & $6.8 \mathrm{mEq} / \mathrm{L}$ & Anti IA-2 Ab & $15.0 \mathrm{U} / \mathrm{mL}$ \\
\hline Chloride & $67 \mathrm{mEq} / \mathrm{L}$ & Anti $\mathrm{Tg} \mathrm{Ab}$ & $585 \mathrm{U} / \mathrm{mL}$ \\
\hline Calcium & $8.9 \mathrm{mg} / \mathrm{dL}$ & Anti TPO Ab & $>600 \mathrm{U} / \mathrm{mL}$ \\
\hline Phosphorus & $14.8 \mathrm{mg} / \mathrm{dL}$ & & \\
\hline
\end{tabular}

TSH: thyroid stimulating hormone, FT3: free triiodothyronine, FT4: free thyroxine, GAD: glutamic acid decarboxylase, IA-2: insulinoma-associated protein 2, Tg: thyroglobulin, TPO: thyroid peroxidase

\section{Case Report}

A 60-year-old Caucasian man was transferred on an emergency basis to our hospital due to persistent nausea, vomiting and respiratory distress. He had arrived in Japan from the United States for business three days earlier. He had suffered from nausea and vomiting since the previous evening and requested an ambulance for himself due to respiratory distress the following morning. He received a diagnosis of type 2 diabetes and began treatment with metformin at 42 years of age, with insulin therapy added three years later. The basis for the diagnosis was uncertain because his past clinical and laboratory data were unavailable. His other medical history included hypertension, dyslipidemia and primary hypothyroidism. His current insulin prescription was insulin aspart before each meal (6 to 10 units), and insulin glargine once in the morning (24 units). His other medications included levothyroxine $100 \mu \mathrm{g}$, losartan $100 \mathrm{mg}$, rosuvastatin $40 \mathrm{mg}$, metformin 1,000 mg, and canagliflozin 300 mg per day. Canagliflozin, a SGLT2 inhibitor, had been added due to poor glycemic control two weeks earlier. After starting the SGLT2 inhibitor treatment, he lost $2 \mathrm{~kg}$ in weight without any adverse effects. He had not taken his medications or insulin injections since the previous evening.

On arrival at our hospital, he looked pale and drowsy with some disorientation (Glasgow Coma Scale of 12; E3V4M5). He was $165 \mathrm{~cm}$ tall and weighed $72.8 \mathrm{~kg}$. His blood pressure was $82 / 43 \mathrm{mmHg}$, body temperature $36.3^{\circ} \mathrm{C}$, pulse 118 beats per minute, respiratory rate 36 breaths per minute without acetone breath, and oxygen saturation 99\% while breathing oxygen at a flow rate of 10 liters per minute through a face mask. A physical examination revealed signs of severe dehydration: dry skin, sticky mouth, and a collapsed jugular vein. An abdominal examination revealed marked distension with the disappearance of bowel sounds, however, he did not complain of any pain. Because his vital signs indicated sustained shock despite the rapid infusion of isotonic saline, a cardiologist was called who performed electrocardiography and echocardiography, although no abnormal findings were detected.

The results of the laboratory examination on admission are shown in Table. A peripheral blood test showed a slight increase in the white blood cell count and C-reactive protein, an impaired renal function with high serum potassium and phosphorus levels, the elevation of pancreatic enzymes, procalcitonin, hyperlactatemia and severe hyperglycemia with high levels of ketone bodies. An arterial blood gas analysis showed metabolic acidosis with a profound elevation of the anion gap. Given the coexistence of diabetic ketoacidosis with metformin-associated lactic acidosis, we immediately started a continuous intravenous infusion of human regular insulin and antibiotics followed by continuous hemodialysis filtration with vasoconstrictor agents. Abdominal computed tomography was performed with suspicion of an acute abdomen, which revealed a dilated diffuse gastroin- 
a)

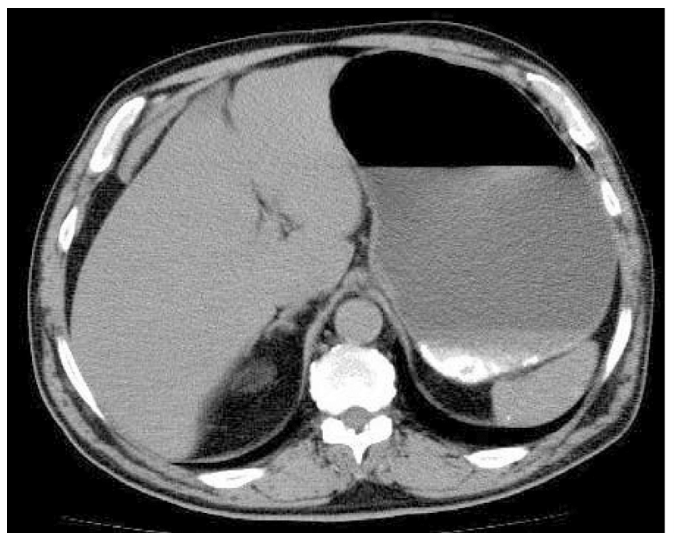

b)

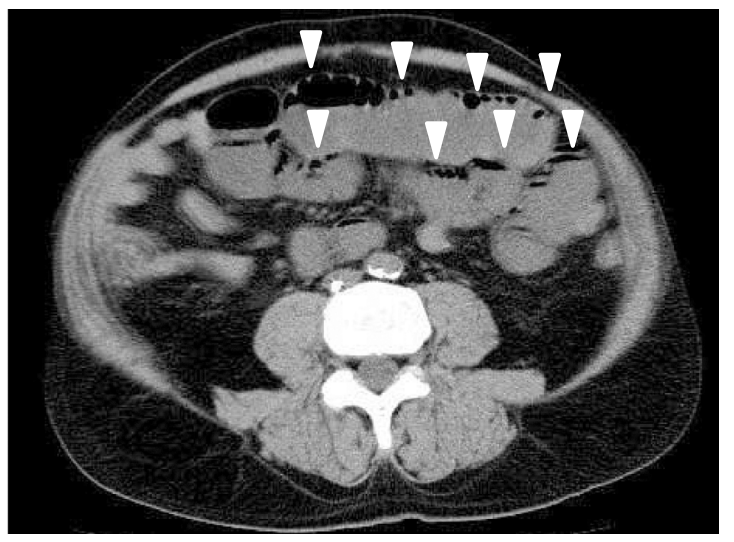

Figure 1. Computed tomography without contrast agent revealed (a) marked dilatation of the diffuse gastrointestinal tract ranging from the stomach to the ileum, (b) accompanied by parietal pneumatosis (arrowheads) and portomesenteric vein gas.

a)

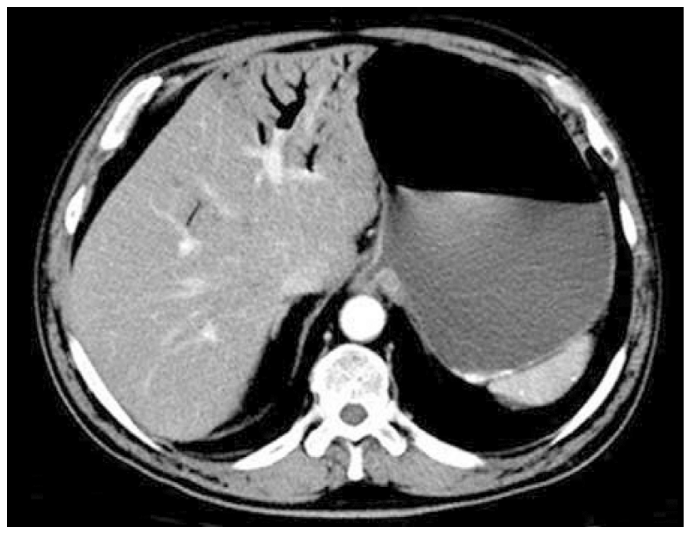

b)

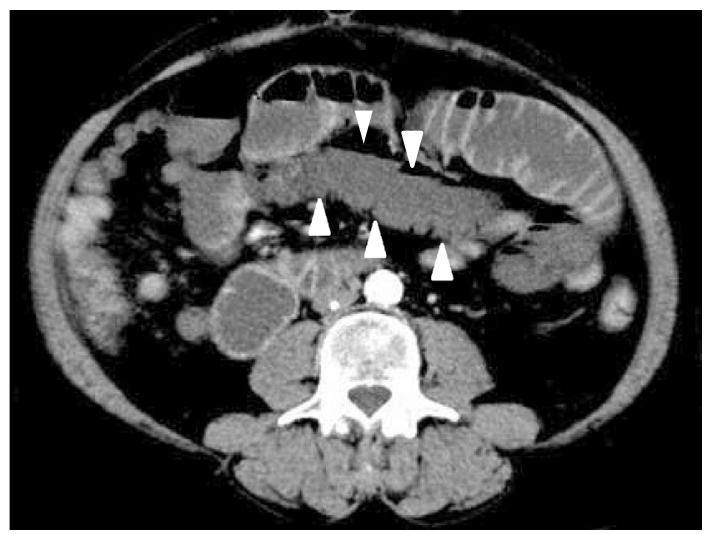

Figure 2. Computed tomography with contrast agent revealed (a) the appearance of intrahepatic portal air and (b) absent enhancement of the ischemic bowel (arrowheads) without any occlusion of the mesenteric vessels.

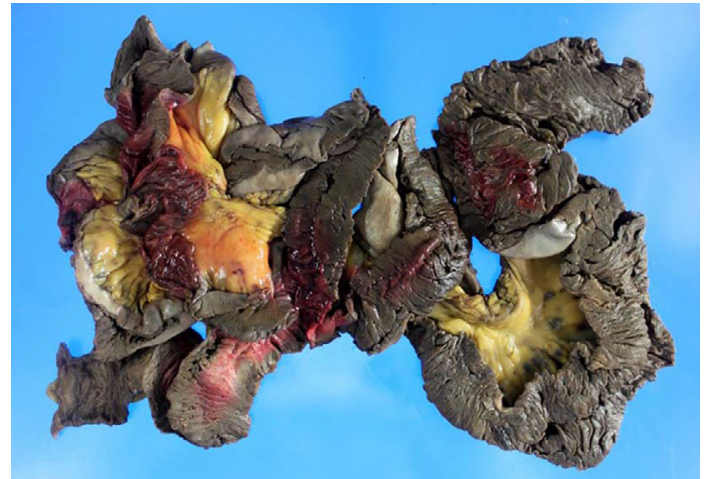

Figure 3. A gross photograph of a resected specimen. The length of the resected bowel is $181 \mathrm{~cm}$ accompanied by diffuse black discoloration, severe congestion, edema and partial hemorrhage.

testinal tract ranging from the stomach to the ileum accompanied by pneumatosis intestinalis and portomesenteric vein gas, indicating acute mesenteric ischemia (Fig. 1). Subse- quent computed tomography with a contrast agent showed a diffuse lack of small bowel wall enhancement and the appearance of intrahepatic portal air, although no vascular occlusion or thrombosis was apparent (Fig. 2). With a presumed diagnosis of developing intestinal necrosis, the patient underwent urgent exploratory surgery. During exploration, segments of the small bowel appeared to be profoundly distended and gangrenous (with black discoloration). The mesenteric arteries were patent with good pulsations without occlusion or thrombosis, whereas the collapse of the mesenteric vein with intravascular bubbles was validated. There were no ascites in the peritoneal cavity. The gangrenous portion of the bowel was resected immediately, followed by end-to-end anastomosis. The resected bowel reached $181 \mathrm{~cm}$ accompanied by severe congestion, edema and partial hemorrhage, although no perforations were evident (Fig. 3). The microscopic findings (Fig. 4) revealed epithelial cell elimination in the small intestinal villi without any mechanical vascular obstruction in the mesenteric vessels, findings that were compatible with NOMI. The histological changes were 

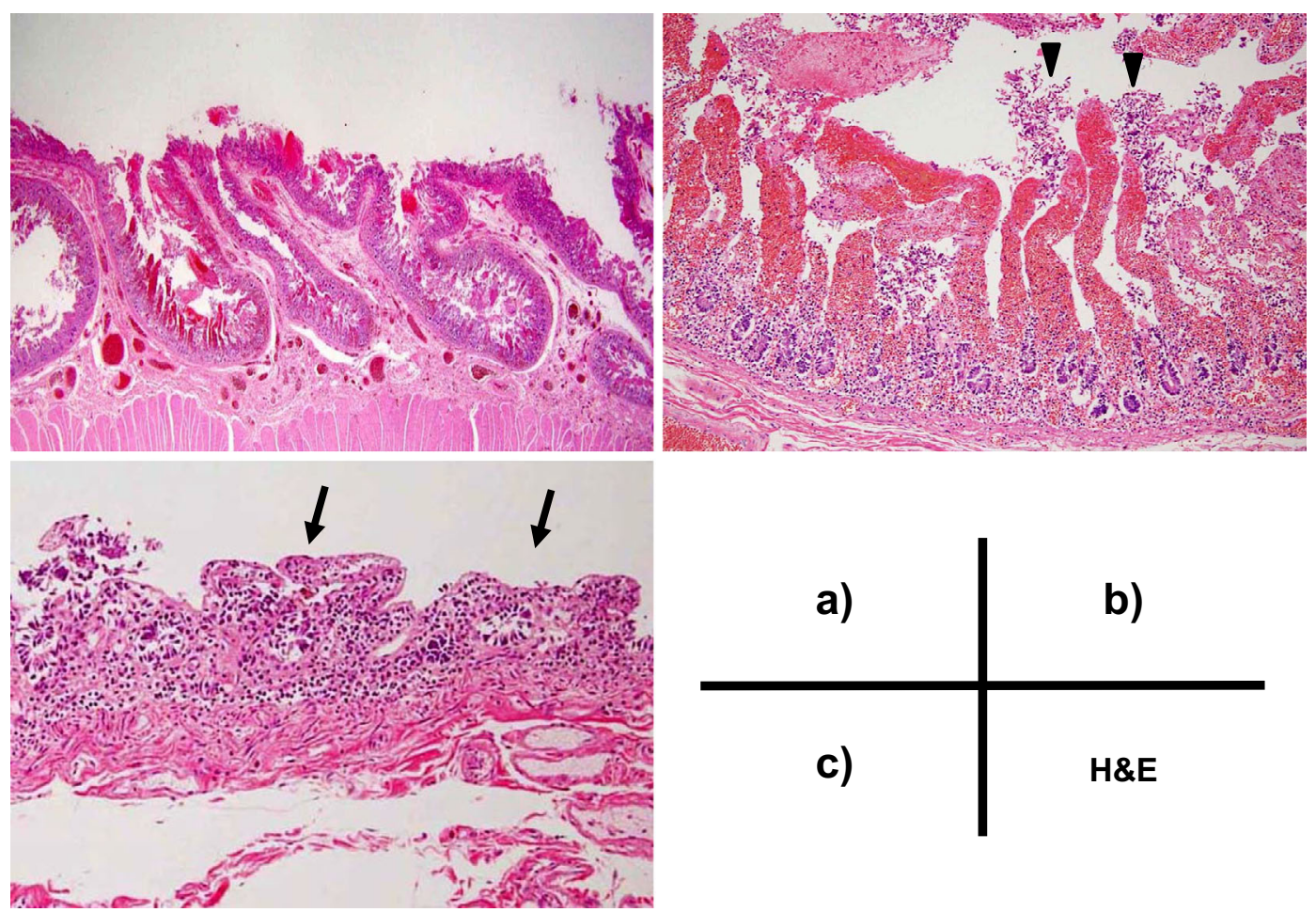

Figure 4. Histological findings (Hematoxylin and Eosin staining, H\&E). a) Diffuse mucosal hemorrhage without extending transmural bowel wall necrosis. b) Shedding of epithelial cells at the villus tip (arrowheads) and congestion in the villus capillaries. c) Disappearance of the intestinal villi (arrows) in patches.

confined to superficial localized lesions without extending transmural gangrene, which appeared to indicate an early stage of ischemia. He was transferred to the intensive care unit after surgery for a sustained shock state and disseminated intravascular coagulation. Subsequently, he was treated with insulin infusion, broad-spectrum antibiotics, catecholamine, recombinant thrombomodulin and continuous hemodialysis filtration with polymyxin B-immobilized fiber for endotoxin absorption. The following day, he regained consciousness with the resolution of hyperlactatemia and a gradually reduced catecholamine requirement. The continuous hemodialysis filtration and catecholamine infusion were discontinued on the third postoperative day, with normalization of the renal function and blood pressure. The levels of pancreatic enzymes also returned to normal; their increased levels were considered to have been the result of an impaired clearance due to acute kidney injury. Diabetic ketoacidosis might cause non-specific elevations of amylase and lipase, although the exact mechanisms remain unclear (11). After discharge from the intensive care unit, multiple subcutaneous insulin injections were resumed, with oral ingestion begun on the sixth day. We maintained the discontinuation of canagliflozin and metformin due to a suspicion of an association with diabetic ketoacidosis and lactic acidosis, in addition to the diagnosis of a slowly progressive type 1 diabetes according to the high titers of glutamic acid decarboxylase (GAD) antibody $(52.3 \mathrm{U} / \mathrm{mL})$ and insulinomaassociated protein 2 (IA-2) antibody $(15.0 \mathrm{U} / \mathrm{mL})$ in combi- nation with a maintained depletion of insulin secretion (2hour postprandial serum C-peptide $<0.10 \mathrm{ng} / \mathrm{mL}$ ). He was discharged on the fifteenth hospital day with insulin intensive treatment: insulin aspart before each meal (6 to 10 units) and insulin glargine twice daily (24 units at breakfast and 6 units at dinner time). He returned home soon after.

\section{Discussion}

We herein reported an extremely rare case of NOMI with diabetic ketoacidosis and lactic acidosis potentially associated with the administration of a SGLT2 inhibitor. The criteria for the diagnosis of NOMI have not yet been established, however, the diagnosis is typically made according to characteristic pathological findings that include segmental ischemic necrosis and hemorrhage of the bowels without mesenteric venous occlusion (12). Recently, several case reports have referred to this condition in association with diabetic ketoacidosis. It is speculated that the hyperglycemic state may induce hypoperfusion of the mesenteric artery related to NOMI, caused by severe dehydration, contracted vascular volume, low cardiac output, increased blood viscosity and other hemostatic changes (13). Furthermore, previous studies have shown that the state of diabetic ketoacidosis activates catecholamines, the renin-angiotensin system (14) and vasopressin excretion (15), which may mediate vasospasms of the mesenteric artery.

In our case, the SGLT2 inhibitor might have contributed 
to the onset of NOMI due not only to its potential to cause osmotic diuresis leading to fluid loss, but also by provoking diabetic ketoacidosis. The U.S. Food and Drug Administration (FDA) released a warning about this adverse effect in May 2015 based on 20 cases with diabetic ketoacidosis and ketosis in patients treated with SGLT2 inhibitors. In these reports, the patients had all been taking SGLT2 inhibitors for an average of two weeks, and the adverse effects may have been triggered by an acute major illness, reduced food or fluid intake, or the discontinuation of insulin, as in our case. The pathology of diabetic ketoacidosis due to SGLT2 inhibitors is speculated to involve decreased urinary excretion of ketone bodies and the promotion of glucagon secretion by affecting SGLT2 expressed in pancreatic alpha cells, thereby leading to increased ketogenesis (16). The FDA has not yet approved SGLT2 inhibitors for use in patients with type 1 diabetes, although several studies mention their effectiveness in such patients as well as an insulin-independent mode of action $(17,18)$. Presumably, our patient had been misdiagnosed with type 2 diabetes complicated by obesity, for which his attending physician prescribed a SGLT2 inhibitor.

NOMI has a very high mortality due to the difficulty in making a prompt diagnosis since the early symptoms and signs, such as abdominal pain, nausea, vomiting, fatigue, weakness and altered consciousness, are not specific. NOMI in our case was much more difficult to recognize because the symptoms appeared to be associated with diabetic ketoacidosis. Therefore, our patient did not complain of abdominal symptoms as in past case reports regarding NOMI with diabetic ketoacidosis. Nearly all reported NOMI cases complicated with diabetic ketoacidosis required surgical treatment for extensive intestinal necrosis, although NOMI in its early stages can be treated conservatively with vasodilating medications such as prostaglandin E1 or papaverine (19). An elevation of serum markers including lactic dehydrogenase, aspartate transaminase, creatine phosphokinase and alkaline phosphatase is reported to be useful for detecting early intestinal ischemia (20), however, these findings were initially absent in our case. Similarly, elevations in the levels of plasma D-dimer (21), procalcitonin and phosphorus (22) have been indicated as potential markers to identify the early stage of acute intestinal ischemia in previous reports, and these were recognized in our patient; however, these parameters are not always specific. Serum lactate has been the serum marker used most frequently to diagnose intestinal ischemia, despite the lack of proven specificity (23). Meanwhile, it is uncertain that the elevation in serum lactate in our patient was due to intestinal necrosis, metforminassociated lactic acidosis, or the coincidence of both pathologies. Metformin-associated lactic acidosis is seldom precipitated by metabolic decompensation, infection, acute kidney or liver failure, cardiovascular collapse, or severe depletion of body fluids (24), the symptoms of which, including nausea, vomiting, abdominal pain, hypotension and tachypnea, potentially overlap with those of intestinal ische- mia (25). Consequently, a few reports mention patients with metformin-associated lactic acidosis mimicking ischemic bowel who were later confirmed to show no ischemic changes at autopsy (26) or by exploratory laparotomy (27). In contrast, NOMI in our case was initially misdiagnosed as metformin-associated lactic acidosis, or these two conditions may have co-existed.

In summary, the present report described a patient with type 1 diabetes suffering from NOMI complicated by diabetic ketoacidosis and lactic acidosis, potentially associated with the administration of a SGLT2 inhibitor. Fortunately, NOMI in our patient was successfully treated by surgical treatment in the early stages, although in general NOMI has a very high mortality rate due to the difficulty in making a prompt diagnosis and reversing the ischemia once it has started. It is still a rather underdiagnosed and underestimated condition due to its lack of specific symptoms and findings on clinical examination. In particular, if complicated by diabetic ketoacidosis or lactic acidosis, the symptoms of NOMI are likely to be obscure or confused with those of these other pathologies. Clinicians treating patients with diabetic ketoacidosis or lactic acidosis in life-threatening conditions must keep in mind the possibility of NOMI, even in the absence of abdominal symptoms. In our case, where type 1 diabetes was confirmed during hospitalization, a SGLT2 inhibitor might have participated in the onset of either NOMI or diabetic ketoacidosis through its adverse effects of dehydration and ketogenesis. Therefore, the administration of SGLT2 inhibitors requires certain exceptions for type 1 diabetes (with particular attention on the slowly progressive type) and cautious monitoring for these adverse effects, especially in the early period following the initiation of treatment.

The authors state that they have no Conflict of Interest (COI).

\section{References}

1. Ende N. Infarction of the bowel in cardiac failure. N Engl J Med 258: 879-881, 1958.

2. Adaba F, Askari A, Dastur J, et al. Mortality after acute primary mesenteric infarction: a systematic review and meta-analysis of observational studies. Colorectal Dis 17: 566-577, 2014.

3. Björck M, Wanhainen A. Nonocclusive mesenteric hypoperfusion syndromes: recognition and treatment. Semin Vasc Surg 23: 54-64, 2010.

4. Trompeter M, Brazda T, Remy CT, Vestring T, Reimer P. Nonocclusive mesenteric ischemia: etiology, diagnosis, and interventional therapy. Eur Radiol 12: 1179-1187, 2000.

5. Ichikawa R, Moriya T, Hosaka T, et al. A case of diabetic ketoacidosis complicated by non-occlusive mesenteric ischemia in type 2 diabetic patient. Tounyoubyou (Journal of the Japanese Diabetes Society) 53: 495-500, 2010 (in Japanese, Abstract in English).

6. Takai T, Takebe R, Ogata M, Katsuyama E, Nakamura T. A type 2 diabetic patient with non-occlusive mesenteric ischemia probably induced by diabetic ketoacidosis due to prednisolone intake. Tounyoubyou (Journal of The Japanese Diabetes Society) 56: 298304, 2013 (in Japanese, Abstract in English).

7. Kamatani N, Katoh T, Sawai Y, et al. A case of diabetic ketoaci- 
dosis comorbid with nonocclusive mesenteric ischemia in a severely dehydrated type 2 diabetic patient. Tounyoubyou (Journal of The Japanese Diabetes Society) 56: 886-891, 2013 (in Japanese, Abstract in English).

8. Oya S, Miyata K, Yuasa N, et al. A case of nonocclusive mesenteric ischemia induced by diabetic ketoacidosis due to fulminant type 1 diabetes. Nihon Syoukaki Geka Gakkai Zasshi (The Japanese Journal of Gastroenterological Surgery) 43: 970-975, 2010 (in Japanese).

9. Ashrafi M, Hashemipour M, Moadab MH, Jamshidi M, Hosseinpour M. Ischemic intestinal necrosis in a five-year-old girl with diabetic ketoacidosis. Arch Iran Med 10: 529-531, 2007.

10. Plosker GL. Canagliflozin: a review of its use in patients with type 2 diabetes mellitus. Drugs 74: 807-824, 2014.

11. Rizvi AA. Serum amylase and lipase in diabetic ketoacidosis. Diabetes Care 26: 3193-3194, 2003.

12. Fogarty TJ, Fletcher WS. Genesis of nonocclusive mesenteric ischemia. Am J Surg 111: 130-137, 1966.

13. DiMeglio LA, Chaet MS, Quigley CA, Grosfeld JL. Massive ischemic intestinal necrosis at the onset of diabetes mellitus with ketoacidosis in a three-year-old girl. J Pediatr Surg 38: 1537-1539, 2003.

14. Worly JM, Fortenberry JD, Hansen I, Chambliss CR, Stockwell J. Deep venous thrombosis in children with diabetic ketoacidosis and femoral central venous catheters. Pediatrics 113: 57-60, 2004.

15. Ferriss JB, O'Hare JA, Kelleher CC, et al. Diabetic control and the renin-angiotensin system, catecholamines, and blood pressure. Hypertension 7: 1158-1163, 1985.

16. Taylor SI, Blau JE, Rother KI. SGLT2 inhibitors may predispose to ketoacidosis. J Clin Endocrinol Metab 100: 2849-2852, 2015.

17. Mudaliar S, Armstrong DA, Mavian AA, et al. Remogliflozin etabonate, a selective inhibitor of the sodium-glucose transporter
2, improves serum glucose profiles in type 1 diabetes. Diabetes Care 35: 2198-2200, 2012.

18. Perkins BA, Cherney DZ, Partridge H, et al. Sodium-glucose cotransporter 2 inhibition and glycemic control in type 1 diabetes: results of an 8-week open-label proof-of-concept trial. Diabetes Care 37: 1480-1483, 2014.

19. Björck M, Wanhainen A. Nonocclusive mesenteric hypoperfusion syndromes: recognition and treatment. Semin Vasc Surg 23: 54-64, 2010.

20. Thompson JS, Bragg LE, West WW. Serum enzyme levels during intestinal ischemia. Ann Surg 211: 369-373, 1990.

21. Altinyollar H, Boyabatli M, Berberoğlu U. D-dimer as a marker for early diagnosis of acute mesenteric ischemia. Thromb Res 117: 463-467, 2006.

22. Karabulut K, Gül M, Dündar ZD, Cander B, Kurban S, Toy H. Diagnostic and prognostic value of procalcitonin and phosphorus in acute mesenteric ischemia. Ulus Travma Acil Cerrahi Derg 17: 193-198, 2011.

23. Demir IE, Ceyhan GO, Friess H. Beyond lactate: is there a role for serum lactate measurement in diagnosing acute mesenteric ischemia? Dig Surg 29: 226-235, 2012.

24. Inzucchi SE, Lipska KJ, Mayo H, Bailey CJ, McGuire DK. Metformin in patients with type 2 diabetes and kidney disease: a systematic review. JAMA 312: 2668-2675, 2014.

25. Peters N, Jay N, Barraud D, et al. Metformin-associated lactic acidosis in an intensive care unit. Crit Care 12: R149, 2008.

26. Correia CS, Bronander KA. Metformin-associated lactic acidosis masquerading as ischemic bowel. Am J Med 125: e9, 2012.

27. Ncomanzi D, Sicat RM, Sundararajan K. Metformin-associated lactic acidosis presenting as an ischemic gut in a patient who then survived a cardiac arrest: a case report. J Med Case Rep 21: 159, 2014.

(C) 2016 The Japanese Society of Internal Medicine http://www.naika.or.jp/imonline/index.html 